\title{
Pharmacological effects of Radix Angelica Sinensis (Danggui) on cerebral infarction
}

Yi-Chian $\mathrm{Wu}^{1}$ and Ching-Liang Hsieh ${ }^{1,2,3^{*}}$

\begin{abstract}
Radix Angelica Sinensis, the dried root of Angelica sinensis (Danggui), is a herb used in Chinese medicine to enrich blood, promote blood circulation and modulate the immune system. It is also used to treat chronic constipation of the elderly and debilitated as well as menstrual disorders. Research has demonstrated that Danggui and its active ingredients, as anti-arthrosclerotic, anti-hypertensive, antioxidant anti-inflammatory agents which would limit platelet aggregation, are effective in reducing the size of cerebral infarction and improving neurological deficit scores.
\end{abstract}

\section{Background}

Danggui, the dried root of Angelica Sinensis (Radix Angelica Sinensis), is a commonly used Chinese medicinal herb to enrich blood, promote blood circulation and treat blood deficiency pattern and menstrual disorders such as dysmenorrhea and irregular menstrual cycle [1]. Wilasrusmee et al. [2] reported that Danggui $(105 \mu \mathrm{g} / \mathrm{ml})$ plays an immunostimulatory role in mitogen-stimulated murine lymphocytes in vitro. Angelan, a purified polysaccharide component of Angelica nakai thought to improve immune function, increases the expression of cytokines in splenocytes as Angelan enhances and the production of interleukin-6 (IL-6) and interferon- $\gamma($ IFN- $\gamma$ ) of activated macrophages, helper $\mathrm{T}$ cells and natural killer cells [3]. The chemical constituents of the Danggui extract are classified into essential oil and water soluble parts including lipid compounds, phenolic compounds, carbohydrates, organic acids and other constituents [4]. The most active ingredients are polysaccharides, Z-Ligustilide (3-butylidene-4,5-dihydrophthalide) and ferulic acid (4hydroxy-3-methoxycinnamicacid) [1].

This article aims to provide an overview of the pharmacological effects of Danggui in reducing the size of cerebral infarction and improving neurological deficit scores.

\section{Search strategy}

We searched Medline, PubMed, Cochrane Library and the China National Knowledge Infrastructure (Chinese

\footnotetext{
* Correspondence: clhsieh@mail.cmuh.org.tw

'Department of Chinese Medicine, China Medical University Hospital,

Taichung 40402, Taiwan

Full list of author information is available at the end of the article
}

language database) between 1990 and 2010, using 'Angelica sinensis', 'Danggui', 'Angelica polysaccharides', 'Z-Ligustilide', 'Ferulic acid' and 'Ischemic stroke' as keywords.

\section{Vasodilation and improving microcirculation}

Nitric oxide (NO) is synthesized with nitric oxide synthase (NOS) which includes three different isoforms, namely endothelial NOS (eNOS), neuronal NOS (nNOS) and inducible NOS (iNOS) [5]. While nNOS and eNOS are induced under different conditions, their activation relies on intracellular $\mathrm{Ca}^{2+}$ for binding calmodulin $[5,6]$. Due to its vasodilative effects, eNOS is considered neuro-protective [6]. Hypertension and a lack of endothelium-derived relaxing factor activity are found in eNOS knockout mice [7]. Moreover, the cerebral infarction size is larger in a model of eNOS mutant mice with middle cerebral artery occlusion (MCAo) [8]. Therefore, eNOS has a vasodilation effect and is neuro-protective by increasing the blood flow [9]. It is possible that Danggui increases NO formation and relaxes the endothelium [10], thereby limiting infarction size. In rabbits on a high-lipid diet, treatment with ferulic acid, an active component of Danggui, increases the generation of NO, thereby inhibiting platelet aggregation on endothelium and proliferation of smooth muscles and preventing leucocytes adhering to the endothelium [11].

Z-Ligustilide (3-butylidene-4,5-dihydrophthalide), a component of Danggui, inhibits $(4-8 \mu \mathrm{g} / \mathrm{ml})$ the spontaneous contraction of isolated rat uterus in a dose-dependent manner [12]. Moreover, Z-Ligustilide may also inhibit prostaglandin F-2 $\alpha$, oxytocin, acetylcholine chloride and potassium depolarization-induced uterine contraction, 
suggesting that Ligustilide modulates the function of uterine tissue and has a non-specific anti-spasmodic effect [12]. Z-Ligustilide enhances the recovery of conjunctival capillary and venue diameter after dextran T500 administration to rabbits and increases the number of opened capillaries as well as blood flow, suggesting that Z-Ligustilide improves microcirculation [13].

Ferulic acid is the main organic acid component of Danggui. Ferulic acid $\left(10^{-3} \mathrm{~mol} / \mathrm{L}\right)$ relaxes the phenylephrine-induced contraction of aorta ring in spontaneous on rat (SHR) whereas the effects of ferulic acid may be partially blocked by pretreatment of the aorta with $N^{G}$ nitro-L-arginine methyl ester (L-NAME, $10^{-4} \mathrm{~mol} / \mathrm{L}$ ) which inhibits the production of NO from L-arginine [14]. Ferulic acid $\left(10^{-3} \mathrm{~mol} / \mathrm{L}\right)$ reduces the production of thromboxane $B_{2}$ in the aorta ring of SHR [14]. Ferulic acid $\left(10^{-4}\right.$ $\mathrm{mol} / \mathrm{L}$ ) also significantly reduces the generation of $\mathrm{NADPH}$-dependent production of the superoxide anion [14] and enhances the acetylcholine-induced vasodilation whereas hydroxyhydroquinone (HHQ) inhibits this effect [14]. Taken together, ferulic acid reduces blood pressure in SHR via effects on (1) eNOS; (2) the inhibition of thromboxane $B_{2}$ to relax aorta ring; (3) reactive oxygen species (ROS) scavenging activity to increase the availability of NO in endothelial cell of aorta [14].

\section{Anti-arthrosclerosis effects}

Stroke is divided into two major groups according to the cerebral damage, cerebral infarction and cerebral hemorrhage. Eighty percent $(80 \%)$ of stroke patient suffer from cerebral infarction [15]. Cerebral infarction is mainly caused by thrombosis, embolism or systemic hemodynamic hypertension. Atherosclerosis in large and small arteries is a major contributor to cerebral thrombosis. The etiology of atherosclerosis and stroke is related to inflammation and genetic factors. Ischemic cerebral infarction may be prevented by anti-inflammatory agents or the treatment of vascular diseases, heart diseases and hypertension [16-18].

A principal contributor to cerebral infarction and atherosclerosis is believed to be initiated by an excessive inflammatory-fibro-proliferative response [19]. Atherosclerosis involves growth factors, cytokines and vaso-regulatory factors such as vascular endothelial growth factor (VEGF), fibroblast growth factor $(\mathrm{FGH})$, transforming growth factor- $\beta$ (TGF- $\beta$ ), interleukin-1 (IL-1) and tumor necrosis factor $-\alpha($ TNF- $\alpha)[19,20]$. Cytokines are both pro- and anti-atherogenic; for example, IL- 1 and TNF- $\alpha$ mediate the production of monocyte chemoattractant protein-1 (MCP-1) to induce monocyte migration directly into the intima. By contrast, cytokines can induce NO production which regulates the vasomotor tone of artery, thereby influencing the initiation and progression of the atherosclerosis process [20]. A previous study [21] found that nicotine can mediate the development and progression of atherosclerosis via the inhibition of TGF- $\beta 1$ and basic fibroblast growth factor (bFGF). The alteration of TGB- $\beta$ activity leads to the atherosclerotic change of vessel wall and increased TGB- $\beta$ signaling plays a protective role of atherosclerosis [22]. A study [23] reported that bFGF enhances smooth muscle migration and proliferation via the regulation of interstitial collagenase expression in the early stages of atherosclerosis. Wang et al. [24] found that the levels of TGB- $\beta$ reduced and those of bFGF increased in human umbilical vein endothelial cells damaged by hyperlipidemic serum. Moreover, under electromicroscopy the morphology of endothelial cell was also damaged which was reversed by Danggui $(20 \mathrm{mg} / \mathrm{ml})$ and its component of sodium ferulate $(0.3 \mathrm{mg} / \mathrm{ml})$. These results indicate that both Danggui and sodium ferulate have anti-atherogenic effects [24]. Yu et al. [25] found that the levels of total cholesterol (TC, $0.95 \mathrm{mmol} / \mathrm{L} v s .11 .79$ $\mathrm{mmol} / \mathrm{L}$ ), triglyceride (TG) and high density lipoprotein cholesterol (HDLC) and low density lipoprotein cholesterol (LDLC) increased in rabbits on a high-lipid diet compared to the control group which was on a normal diet. After 25\% Danggui was administered (i.v.) for four weeks, the levels of TG decreased from $3.52 \mathrm{mmol} / \mathrm{L}$ to 1.68 $\mathrm{mmol} / \mathrm{L}$. The plaque area of thoracic aorta was also reduced after Danggui treatment, from $63.31 \%$ to $35.58 \%$ [25]. Moreover, Danggui reduced the increase of the serum malonyldialdehyde (MDA) levels caused by the high-lipid diet [25]. In a similar study [11], after treatment with sodium ferulate, the plaque area of thoracic aorta was reduced while the TG level was reduced to $1.75 \mathrm{mmol} / \mathrm{L}$ in rabbits on a high-lipid diet [11]. Moreover, the sodium ferulate-treated group increased the production of NO from epithelium cells. Both Danggui and sodium ferulate inhibit the formation of atherosclerosis because Danggui reduces the TG and lipid peroxidation levels or increases NO production, or both.

\section{Anti-platelet aggregation effects}

Anti-platelet aggregation agents such as aspirin, ticlopidine and clopidogrel are widely used to prevent secondary ischemic stroke $[16,26]$. A clinical trial [26] reported that administration of aspirin within six hours of the onset of ischemic stroke reduces the patients' mortality rate.

Danggui dose-dependently inhibited adenosine diphosphate (ADP)-induced platelet aggregation and collageninduced platelet [27]. Danggui $(20 \mathrm{~g} / \mathrm{kg})$ reduced platelet aggregation by $87.9 \%$ in rats with ADP-induced platelet aggregation and $33.0 \%$ in rats with collagen-induced platelet aggregation [27]. Administration of sodium ferulate $(0.2 \mathrm{~g} / \mathrm{kg}$, i.v. $)$ reduced ADP-induced platelet aggregation by $38 \%$ in rats while a lower dose $(0.1 \mathrm{~g} / \mathrm{kg})$ reduced 
collagen-induced platelet aggregation by $81 \%$ [27]. In an arteriovenous shunt rat model, the wet weight of the thrombus was reduced to $19.5 \mathrm{mg}$ ( $46.4 \mathrm{mg}$ in the control) in rats administered with Z-Ligustilide $(10 \mathrm{mg} / \mathrm{kg}$, p.o.) and $13.6 \mathrm{mg}$ in rats administered with more ZLigustilide (40 mg/kg, p.o.) [28]. The maximal platelet aggregation was $6.8 \%$ and $2.0 \%$ in the $10 \mathrm{mg} / \mathrm{kg}$ and 40 $\mathrm{mg} / \mathrm{kg}$ groups respectively while the control was $44.6 \%$ [28]. Compared with warfarin (1.0 mg/kg, p.o.), Z-Ligustilide $(10 \mathrm{mg} / \mathrm{kg}$ and $40 \mathrm{mg} / \mathrm{kg})$ administered orally for three days did not increase activated partial thromboplastin time (APTT) and prothrombin time (PT) in a coagulation time test ex vivo [28]. Danggui and Z-Ligustilide exert anti-platelet aggregation effects.

\section{Anti-inflammatory effects}

Pro-inflammatory cytokines, such as IL- $1 \beta$ and TNF- $\alpha$, are increased in the brain tissue of transient middle cerebral artery occlusion (MCAo) rats [29,30]. IL-1 up-regulates the expression of adhesion molecules such as intercellular adhesion molecule-1 (ICAM-1), P-selectin and E-selectin in the endothelium [31,32]. These adhesion molecules facilitate the translocation of activated leukocytes into the ischemic core $[31,32]$. Moreover, nuclear factor- $\kappa \mathrm{B}$ (NF$\kappa \mathrm{B})$ is also activated in the ischemic core [32]. Both Sophora japonica L. and paeoniflorin inhibit IL-1 $\beta$ secretion, thereby reducing cerebral infarction size and neurological deficit [29]. Moreover, paeoniflorin reduces IL-1 $\beta$, TNF- $\alpha$, ICAM-1 and leucocytes [30]. Therefore, antiinflammation, such as inhibition of pro-inflammatory cytokine and ICAM-1, is very important in treating cerebral infarction.

Ferulic acid (eg 80 and $100 \mathrm{mg} / \mathrm{kg}$, i.v.) reduces the size of cerebral infarction and neurological deficit scores and inhibits ICAM- 1 and NF- $\kappa$ B expression in transient MCAo rats [33]. The anti-inflammatory action of ferulic acid is, at least in part, important in its therapeutic effect on cerebral infarct [33]. Moreover, ferulic acid (eg $100 \mathrm{mg} / \mathrm{kg}$, i.v.) exerts anti-inflammatory action by reducing the generation of 4-hydroxy-2-nonenal (4-HNE), 8-hydroxy-2'-deoxyguanosine (8-OHdG) and apoptosis in the reperfusion period after cerebral ischemia, thus providing neuroprotection [32]. This neuro-protection by ferulic acid is thought to occur via enhancing gamma-aminobutyric acid type B1 $\left(\mathrm{GABA}_{\mathrm{B} 1}\right)$ receptor expression to against p38 mitogen activated protein kinase (MAPK)-mediated NO-induced apoptosis [34]. Danggui reduces inflammatory cell infiltration and TNF- $\alpha$ and TGF- 31 mRNA expression; it also reduces TNF- $\alpha$ and TGF- $\beta 1$ positive cells in radiation-induced pneumonitis in mice [35]. Danggui polysaccharides reduce TNF- $\alpha$ levels in the colon mucosa during intra-colon enema with 2,4,6-trinitrobenzene sulfonic acid (TNBS) and ethanol in rats [36]. Both Danggui and ferulic acid exert anti-inflammatory effects.

\section{Anti-oxidative effects}

Reactive oxygen species (ROS) including the superoxide anion, hydrogen peroxide and hydroxyl radical are generated after cerebral ischemia. The ROS affect mitochondrial function, DNA repair and transcription factors, leading to apoptosis $[37,6]$. Superoxide dismutase 1 (SOD1), an endogenous antioxidant, blocks the early release of cytochrome c from mitochondria and reduces the development of apoptosis in focal cerebral ischemic mice [38]. Apolipoprotein E, via its anti-oxidative effects against cerebral ischemia, is neuro-protective in transient forebrain ischemia induced by bilateral common carotid artery occlusion (BCCAo) in mice [39]. Anti-oxidant nutrients such as vitamin E and Ginkgo biloba extract reduce cerebral damage in rodent models of ischemia and reperfusion [40]. GABA ${ }_{B}$ receptor agonist baclofen may be neuro-protective via the inhibition of N-methyl-D-asparate (NMDA) receptor-mediated $\mathrm{NO}$ production in brain ischemic injury [41]. Ferulic acid (100 mg/kg, i.v.) enhanced the expression of $\mathrm{GABA}_{\mathrm{B} 1}$ in the reperfusion period (three and 24 hours after ischemia) in rats [34]. Z-ligustilide reduced the size of cerebral infarction from $22.1 \%$ to $11.8 \%$ (5 mg/kg, i.p.) and $2.60 \%$ (20 $\mathrm{mg} / \mathrm{kg}$, i.p.) [42]. Z-ligustilide reduced the MDA levels and increased glutathione peroxidase (GSH$\mathrm{Px}$ ) and SOD activities in the ischemia-reperfusion brain tissues induced by BCCAo in mice [42]. Danggui or its components or both demonstrate anti-oxidant activity in ischemia-reperfusion injury models.

\section{Effect of Danggui on cerebral infarction}

Danggui (5 g/kg, i.p.) increased blood circulation and neuronal metabolism in an MCAo rat model [43]. Danggui reduced the size of cerebral infarction, neurological deficit scores and increased blood flow and SOD activity in the MCAo rat model [44]. Z-ligustilide reduced cerebral infarction size to $10.90 \%$ and $3.19 \%$ in rats orally dosed with $20 \mathrm{~m} / \mathrm{kg}$ or $80 \mathrm{mg} / \mathrm{kg}$ respectively $(21.08 \%$ in the control group) in a MCAo model [45]. Moreover, Z-ligustilide (10 mg/kg or $40 \mathrm{mg} / \mathrm{kg}$, p.o.) increased choline acetyltransferase activity and inhibited acetylcholinesterase to improve cognitive function in rats with hypoperfusion [46]. Our previous study [33] found that ferulic acid $(80 \mathrm{mg} / \mathrm{kg}$ or $100 \mathrm{mg} / \mathrm{kg}$, i.v.) reduced cerebral infarction size and neurological deficit scores in rats. Liu et al. [47] reported that Danggui (25\%, i.v.) administered to 1040 patients with acute cerebral infarction improved neuro-function scores and the Barthel index score more than Salvia miltiorrhiza (78.7\% vs. $59.3 \%)$. Danggui reduces the size of cerebral infraction and improves neurological deficit scores.

\section{Conclusion}

The effects of Danggui on cerebral infarction are through multiple pathways, including anti-arthrosclerosis, 
Table 1 Possible pharmacological actions of Radix Angelica Sinensis on cerebral infarction

\begin{tabular}{|c|c|c|}
\hline Pharmacological actions & $\begin{array}{l}\text { Related } \\
\text { components }\end{array}$ & Possible mechanisms \\
\hline \multirow[t]{3}{*}{ Anti-arthrosclerosis effects } & $\begin{array}{l}\text { Danggui and } \\
\text { sodium ferulate }\end{array}$ & reverse the reduction of TGB- $\beta /$ reverse the increase of bFGF [24] \\
\hline & Danggui & reduce the increase of serum malonyldialdehyde (MDA) levels [25] \\
\hline & sodium ferulated & decrease the levels of triglyceride [11] \\
\hline \multirow{5}{*}{$\begin{array}{l}\text { Vasodilatation and improving } \\
\text { microcirculation effects }\end{array}$} & Danggui & increase the formation of $\mathrm{NO}$ and mediate the inhibition of calcium influx [10] \\
\hline & sodium ferulate & increase the generation of NO [11] \\
\hline & Ligustilide & $\begin{array}{l}\text { inhibit prostaglandin F-2 } \alpha \text {, oxytocin, acetylcholine chloride, and potassium } \\
\text { depolarization-induced muscle contraction [12] }\end{array}$ \\
\hline & Ligustilide & increase the number of opened capillary and the speed of blood flow [13] \\
\hline & Ferulic acid & $\begin{array}{l}\text { enhance acetylcholine-induced vasodilatation and reduce the production of } \\
\text { thromboxane } B_{2}[14]\end{array}$ \\
\hline \multirow[t]{2}{*}{ Anti-platelet aggregation effects } & $\begin{array}{l}\text { Danggui and } \\
\text { sodium ferulate }\end{array}$ & inhibit ADP-induced and collagen-induced platelet aggregation [27] \\
\hline & Z-Ligustilide & inhibit ADP-induced platelet aggregation [28] \\
\hline \multirow[t]{4}{*}{ Anti-inflammatory effects } & Ferulic acid & inhibit ICAM-1 and NF- $\kappa$ B expression [33] \\
\hline & Ferulic acid & enhance gamma-aminobutyric acid type $\mathrm{B} 1\left(\mathrm{GABA}_{\mathrm{B} 1}\right)$ receptor expression [34] \\
\hline & Danggui & reduce TNF- $\alpha$ and TGF- $\beta 1$ mRNA expression [35] \\
\hline & $\begin{array}{l}\text { Danggui } \\
\text { polysaccharides }\end{array}$ & reduce TNF- $\alpha$ levels [36] \\
\hline \multirow[t]{3}{*}{ Anti-oxidative effects } & Ferulic acid & reduce the generation of NADPH-dependent production of superoxide anion [14] \\
\hline & Ferulic acid & enhances the expression of $\mathrm{GABA}_{B 1}$ receptor expression [34] \\
\hline & Z-ligustilide & reduce MDA levels and increase GSH-PX and SOD activities [42] \\
\hline
\end{tabular}

improving microcirculation, anti-platelet aggregation, anti-inflammatory and anti-oxidative effects (Table 1). Danggui may be useful in treating the cerebral infarction type of stroke.

\footnotetext{
Abbreviations

IL: interleukin; IFN- $\gamma$ : interferon- $\gamma$; AP: polysaccharide component; ALT: serum alanine transferase; MDA: malondialdehyde; NOS: nitric oxide synthase; $C C_{4}$ : carbon tetrachloride; ASP: water-soluble polysaccharide; NO: nitric oxide; eNOS: endothelial nitric oxide synthase; nNOS: neuronal nitric oxide synthase;iNOS: inducible nitric oxide synthase; MCAo: middle cerebral artery occlusion; L-NAME: $N^{G}$-nitro-L-arginine methyl ester; SHR: spontaneous hypertensive rat; NADPH:nicotinamide adenine dinucleotide phosphate; $\mathrm{HHQ}$ : hydroxyhydroquinone; ROS: reactive oxygen species; VEGF: vascular endothelial growth factor; FGH: fibroblast growth factor; TGF- $\beta$ : transforming growth factor- $\beta$; TNF-a: tumor necrosis factor - $\alpha$; MCP-1: monocyte chemoattractant protein-1; bFGF: basic fibroblast growth factor; TC: total cholesterol; TG: triglyceride; HDLC: high density lipoprotein cholesterol; LDLC: low density lipoprotein cholesterol; ADP: adenosine diphosphate; APTT: activated partial thromboplastin time; PT: prothrombin time; ICAM-1: intracellular adhesion molecule-1; NF-kB: nuclear factor-KB; 4-HNE: 4-hydroxy2-nonenal; 8-OHdG: 8-hydroxy-2'-deoxyguanosine; GABA B1 $_{\text {: gamma- }}$ aminobutyric acid type B1; MAPK: mitogen activated protein kinase; mRNA: messenger ribonucleic acid; SOD: superoxide dismutase; NMDA: N-methyl-Dasparate; GSH-Px: glutathione peroxidase; BCCAo: bilateral carotid artery occlusion
}

\section{Acknowledgements}

This study is supported in part by the Clinical Trial and Research Center of Excellence (DOH100-TD-B-111-004), Department of Health, Taiwan.

\section{Author details}

${ }^{1}$ Department of Chinese Medicine, China Medical University Hospital, Taichung 40402, Taiwan. ${ }^{2}$ Graduate Institute of Acupuncture Science, China Medical University, Taichung 40402, Taiwan. ${ }^{3}$ Acupuncture Research Center, China Medical University, Taichung 40402, Taiwan.

\section{Authors' contributions}

YCW searched the literature, organized the information and wrote the manuscript. CLH analyzed the information and revised the manuscript. Both authors read and approved the final version of the manuscript.

\section{Competing interests}

The authors declare that they have no competing interests.

Received: 1 March 2011 Accepted: 25 August 2011

Published: 25 August 2011

\section{References}

1. Hou TC: In Herbal Extracts. Volume 1.. 1 edition. Beijing: China Medical Scientific Technological Publishing Company; 2004:173-183, In Chinese.

2. Wilasrusmee C, Kittur S, Siddiqui J, Bruch D, Wilasrusmee S, Kittur DS: In Vitro immunomodulatory effects of ten commonly used herbs on murine lymphocytes. J Altern Complement Med 2002, 8(4):467-475.

3. Han SB, Kim YH, Lee CW, Park SM, Lee HY, Ahn KS, Kim IH, Kim HM: Characteristic immunostimulation by angelan isolated from Angelica gigas Nakai. Immunopharmacology 1998, 40(1):39-48.

4. Huang LF, Li BY, Liang YZ, Guo FQ, Wang YL: Application of combined approach to analyze the constituents of essential oil from Dong Quai. Anal Bioanal Chemist 2004, 378(2):510-517.

5. Michel T, Feron O: Nitric oxide synthases: which, where, how, and why? Clin Invest 1997, 100:2146-2152

6. Chan PH: Reactive oxygen radicals in signaling and damage in the ischemic brain. J Cereb Blood Flow Metab 2001, 21(1):2-14. 
7. Huang PL, Huang Z, Mashimo H, Bloch KD, Moskowitz MA, Bevan JA, Fishman MC: Hypertension in mice lacking the gene for endothelial nitric oxide synthase. Nature 1995, 377:239-242.

8. Huang Z, Huang PL, Ma J, Meng W, Ayata C, Fishman MC, Moskowitz MA: Enlarged infarcts in endothelial nitric oxide synthase knockout mice are attenuated by nitro-L-arginine. J Cereb Blood Flow Metab 1996, 16:981-987.

9. Huang PL: Neuronal and endothelial nitric oxide synthase gene knockout mice. Braz J Med Biol Res 1999, 32(11):1353-1359.

10. Rhyu MR, Kim JH and Kim EY: Radix Angelica elicits both nitric oxidedependent and calcium influx-mediated relaxation in rat aorta. J Cardiovasc Pharmacol 2005, 46(1):99-104.

11. Wang B, Ouyang J, Liu Y, Yang J, Wei L, Li K, Yang H: Sodium ferulate inhibits atherosclerogenesis in hyperlipidemia rabbits. J Cardiovasc Pharmacol 2004, 43(4):549-554.

12. Du J, Bai B, Kuang X, Yu Y, Wang C, Ke Y, Xu Y, Tzang AHC, Qian ZM: Ligustilide inhibits spontaneous and agonists- or K+ depolarizationinduced contraction of rat uterus. J Ethnopharmacol 2006, 108(1):54-8.

13. Shi LF, Zheng XM, Cai $Z$ and Wu BS: Comparison of influence of essential oil from Ligusticum chuanxiong Hort. on microcirculation in rabbit conjunctiva bulbar before and after decomposition of ligustilide. Chin J Pharmcol Toxicol 1995, 9:157-8.

14. Suzuki A, Yamamoto M, Jokura H, Fujii A, Tokimitsu I, Hase T, Saito I: Ferulic acid restores endothelium-dependent vasodilation in aortas of spontaneously hypertensive rats. Am J Hypertens 2007, 20:508-513.

15. Dietl M, Pohle R, Weingärtner $M$, Polgar R, Grässel $E$, Schwab S, KolominskyRabas P: Stroke etiology and long-term need of care in ischemic stroke patients. Fortschr Neurol Psychiatr 2009, 77(12):714-719.

16. Albers GW, Amarenco P, Easton JD, Sacco RL, Teal P: Antithrombotic and thrombolytic therapy for ischemic stroke: American college of chest physicians evidence-based clinical practice guidelines. Chest , 8 2008, 133(6):630S-669S.

17. Mostaza JM, Martín-Jadraque R, Vicente I, San Martin MA, Lahoz C: Patients at high risk of cerebrovascular disease: the REACH study. Cerebrovasc Dis 2009, 27(supp1):77-81.

18. Liu LS, Caguioa ES, Park CG, Quek DKL, Saito I, Venketasubramanian N Wong KSL, Reid JL: Reducing stroke risk in hypertensive patients: Asian Consensus Conference recommendations. Int J Stroke 2006, 1(3):150-157.

19. Ross R: The pathogenesis of atherosclerosis: a perspective for the 1990s. Nature 1993, 362:801-809.

20. Libby P, Sukhova G, Lee RT, Galis ZS: Cytokines regulate vascular functions related to stability of the atheroscherotic plaque. J Cardiovasc Pharmacol 1995, 25(Supp 2):S9-S12.

21. Cucina A, Corvino V, Sapienza P, Borrelli V, Lucarelli M, Scarpa S, Strom R, Angelo LSD, Cavallaro A: Nicotine regulates basic fibroblastic growth factor and transforming growth factor beta-I production in endothelial cells. Biochem Biophys Res Commun 1999, 257(2):306-312.

22. Grainger DJ: TGF- $\beta$ and atherosclerosis in men. J Cardiovasc Dis Res 2007 174:213-222.

23. Kennedy SH, Rouda S, Qin H, Aho S, Selber J, Tan EML: Basic FGF regulates interstitial collagenase gene expression in human smooth muscle cells. J Cell Biochem 1997, 65(1):32-41.

24. Wang BH, Ou-Yang JP, Wei L, Liu YM, Zheng HQ, Tu SZ: Effects of Angel ica and Sodium Ferulate on the Expressions of TGFB1 and bFGF in the Endothelial Cells. Liaoning Zhongyi Zazhi 2001, 28(1):45-47, In Chinese.

25. Yu Z, Ou-Yang JP, Liu YM, Zheng HQ, Yang JW, Tu SZ and Yang HL: The Anti-atherogenetic Effect of Angelica in Rabbits Aorta. Zhongguo Dongmai Yinghua Zazhi 2000, 8(1):46-48, In Chinese.

26. Bednar MM, Gross CE: Antiplatelet therapy in acute cerebral ischemia. Stroke 1999, 30(4):887-893.

27. Yin ZZ, Zhang LY, Xu LN: The effect of Dang-Gui (Angelica Sinensis) and its ingredient ferulic acid on rat platelet aggregation and release of 5HT. Acta Pharmaceutica Sinica 1980, 15(6):321-326, In Chinese

28. Zhang L, Du JR, Wang J, Yu DK, Chen YS, He Y, Wang CY: Z-ligustilide extracted from Radix Angelica Sinensis decreased platelet aggregation induced by ADP ex vivo and arterio-venous shunt thrombosis in vivo in rats. Yakugaku Zasshi 2009, 127(7):855-859.

29. Lao CJ, Lin JG, Kuo JS, Lee Chao PD, Cheng CY, Tang NY, Hsieh CL: Microglia, apoptosis and interlukin-1 $\beta$ expression in the effect of Sophora Japonica L. on cerebra; infarct induced by ischemia-reperfusion in rats. Am J Chin Med 2005, 33(3):425-438.
30. Tang NY, Liu CH, Hsieh CT, Hsieh CL: The anti-inflammation effect of Paeoniflorin on cerebral infarction induced by ischemia-reperfusion injury in Sprague-Dawley rats. Am J Chin Med 2010, 38(1):51-64.

31. Yang GY, Mao Y, Zhou LF, Gong C, Ge HL, Betz AL: Expression of intercellular adhesion molecule 1 (ICAM-1) is reduced in permanent focal cerebral ischemic mouse brain using an adenoviral vector to induce overexpression of interleukin-1 receptor antagonist. Mol Brain Res 1999, 65(2):143-150.

32. Cheng CY, Su SY, Tang NY, Ho TY, Chiang SY, Hsieh CL: Ferulic acid provides neuroprotection against oxidative stress-related apoptosis after cerebra; ischemia/reperfusion injury by inhibiting ICAM-1 mRNA expression in rats. Brain Res 1209 2008, 136-150.

33. Cheng CY, Ho TY, Lee EJ, Su SY, Tang NY, Hsieh CL: Ferulic acid reduces cerebral infarct through its antioxidative and anti-inflammatory effects following transient focal cerebral ischemia in rats. Am J Chin Med 2008, 36(6):1105-1119.

34. Cheng CY, Su SY, Tang NY, Ho TY, Lo WY, Hsieh CL: Ferulic acid inhibits nitric oxide-induced apoptosis by enhancing $\mathrm{GABA}_{\mathrm{B} 1}$ receptor expression in transient focal cerebral ischemia in rats. Am J Chin Med 2010, 31(8):889-899.

35. Xie CH, Zhang MS, Zhou YF, Han G, Cao Z, Zhou FX, Zhang G, Luo ZG, Wu JP, Liu H, Chen J, Zhang WJ: Chinese medicine Angelica Sinensis suppresses radiation induced expression of TNF- $\alpha$ and TGF- $ß 1$ in mice. Onco Rep 2006, 15:1429-1436

36. Liu SP, Dong WG, Wu DF, Luo HS and Yu JP: Protective effect of Angelica Sinensis polysaccharide on experimental immunological colon injury in rat. World J Gastroenterol 2003, 9(12):2786-2790.

37. Siesjo BK: Pathophysiology and treatment of focal cerebral ischemia Part II: Mechanisms of damage and treatment. J Neurosurg 1992, 77(3):337-354

38. Fujimura M, Morita-Fujimura $Y$, Noshita N, Sugawara T, Kawase M, Chan PH: The cytosolic antioxidant copper/zinc-superoside dismutase prevent the early release of mitochondrial cytochrome $\mathrm{c}$ in ischemic brain after transient focal cerebral ischemia in mice. J Neurosci 2000, 20(8):2817-2824.

39. Kitagawa K, Matsumoto M, Kuwabara K, Takasawa K, Tanaka S, Sasaki T, Matsushita K, Ohtsuki T, Yanagihara T, Hori M: Protective effect of apolipoprotein $\mathrm{E}$ against ischemic neuronal injury is mediated through antioxidant action. J Neurosci Res 2002, 68(2):226-232.

40. Katsumi I, Hiroko N, Yukio Y: Antioxidant nutrients and hypoxia/ischemia brain injury in rodents. Toxicology 2003, 189(1-2):55-61.

41. Tuttolomondo A, Di Sciacca R, Di Raimondo D, Arnao V, Renda C, Pinto A Licata G: Neuron protection as a therapeutic target in acute ischemic stroke. Curr Top Med Chem 2009, 9(14):1317-1334.

42. Kuang X, Yao Y, Du JR, Liu YX, Wang CY, Qian ZM: Neuroprotective role of Z-ligustilide against forebrain ischemic injury in ICR mice. Brain Res 2006, 1102:145-153.

43. Liao WJ, Fan M, Yang YH, Yang WT, Liu ML: Effects of Angelica sinensis injection on the neuronal metabolites and blood flow speed within reperfusion following the ischemic cerebral injury in rats. Zhongguo Yingyong Shenglixue Zazhi 2003, 19(3):209-212, In Chinese.

44. Zhao XQ, Ji XM, Shi WJ: Angelica against cerebral ischemia/reperfusion injury. Zhongguo Meitan Gongye Yixue Zazhi 2009, 12(11):1773-1774, In Chinese

45. Peng HY, Du JR, Zhang GY, Kuang X, Liu YX, Qian ZM, Wang CY: Neuroprotective effect of Z-ligustilide against permanent focal ischemic damage in rats. Biol Pharm Bull 2007, 30:309-312.

46. Kuang $X$, Du JR, Liu YX, Zhang GY, Peng HY: Postischemic administration of Z-Ligustilide ameliorates cognitive dysfunction and brain damage induced by permanent forebrain ischemia in rats. Pharmacol Biochem Behav 2008, 88:213-221.

47. Liu YM, Zhang JJ, Jiang J: Observation on clinical effect of Angelica injection in treating acute cerebral infarction. Zhongguo Zhongxiyi Jiehe Zazhi 2004, 24(3):205-208, In Chinese.

doi:10.1186/1749-8546-6-32

Cite this article as: Wu and Hsieh: Pharmacological effects of Radix Angelica Sinensis (Danggui) on cerebral infarction. Chinese Medicine 2011 6:32. 